\title{
Article
}

\section{Investigation of nanostructured iron oxides as anodic material for water splitting}

\author{
Masood Rauf Khan ${ }^{1, *}$, Zahid Sarfraz ${ }^{1}$ and Hafiz Sami ur Rehman ${ }^{2}$ \\ 1 Department of Physics, University of Trento, Trento, Italy. \\ 2 Department of Materials and Production Engineering, University of Trento, Trento, Italy.; \\ h.samiurrehman@studenti.unipi.it \\ * Correspondence: masoodrauf.khan@alumni.unitn.it
}

Received: 22 September 2019; Accepted: 20 October 2019; Published: 11 November 2019.

\begin{abstract}
We explore the possibility of using an iron-based anodic material ( $\alpha$-hematite) synthesized with a hierarchical 3D urchin-like morphology, as an OER catalyst. The electrodes are prepared by pulsed laser deposition followed by thermal annealing leading to the hierarchical 3D urchin-like morphology. The effect of the deposition parameter on the catalyst phase and morphology are investigated by microRaman spectroscopy and scanning electron microscopy, while the electrode metrics are determined by voltammetric methods and Tafel analysis. We observe that the material is highly electroactive towards the OER, with performance in-line with that of noble-metal based state-of-the-art catalysts.
\end{abstract}

Keywords: Hierarchical 3D, $\alpha$-hematite, PLD, catalysts, overpotential, Tafel slope.

\section{Introduction}

$\mathbf{T}$ o reduce our dependence on fossil fuels and reduce the emission of carbon dioxide, a large scale transition toward sustainable energy sources is necessary [1]. In this regards Hydrogen could play an important role in our modern life. It is a promising energy carrier, which could have a low impact on the environment and its energy content is 10 times greater than fossil fuels. Hydrogen production through the water splitting is a cheapest and clean source of energy [2]. On large scale production of hydrogen from the water splitting, largely depend upon the catalysts that are require to overcome the challenging requirement thermodynamically and kinetics of this half reaction [3,4]. From an electrochemical point of view, it can be split into the two half reactions:

$$
\begin{gathered}
\mathrm{H}_{2} \mathrm{O} \rightarrow 2 \mathrm{H}^{+}+\frac{1}{2} \mathrm{O}_{2}(\text { gas }) \quad(O E R) \\
2 \mathrm{H}^{+}+e^{-} \rightarrow 2 \mathrm{H}_{2}(\text { gas }) \quad(H E R)
\end{gathered}
$$

The oxygen evolution reaction (OER) is a key reaction and often the rate-determining step in electrochemical and Photoelectrochemical water splitting, which is a promising route to carbon-free hydrogen production. For this process we require the OER catalysts which are close to the state- of art catalysts. Iron oxide ( $\alpha$-hematite) because it has been identified as a suitable water oxidation catalyst [5-10], conjugating an overall good performance in both electrolysis and solar water splitting schemes with the advantage of being earth-abundant, non-toxic and environmentally safe.

Pulsed-laser deposition (PLD) of thin films is a technique that employs high-energy-density laser pulses to generate, in the regime of phase explosion, ablated material from a solid target, consisting of a mixture of vapor/liquid nanodroplets. PLD could present some significant advantages over the methods listed above: precise control of the quantity of the deposited material, enhanced adhesion due to the energetic nature of the process, and, most importantly, the possibility of nanostructuring the surface by the deposition of nanoparticles (NPs) [11,12]. Additionally, being essentially a physical deposition method, it is suitable to all kind of substrates. The main drawback of the PLD technique is the need of specialized equipment, although this is already employed in industrial applications. 


\section{Materials and Methods}

The target for the Pulse laser deposition consisted of the cold pressed with a pressure of about $450-$ $500 \mathrm{Kg} / \mathrm{cm}^{2}$ for two times consecutively powders of Fe and Boric acid. Two sets of electrodes, fabricated on the FTO substrates with different thickness by changing the number of pulses: 5000 pluses for the thinner samples and 10000 pulses for the thicker samples. The fluency of the laser was fixed at $3 \mathrm{~J} / \mathrm{cm}^{2}$ and the deposition was carried out in a reactive oxygen atmosphere, at a pressure of $1.5 \times 10^{-2}$ mbar. The number of pulses set at 5000 and the repetition rate at $20 \mathrm{~Hz}$. The coatings were deposited on FTO substrates, with a target - substrate distance of $4.5 \mathrm{~cm}$. All the sample were subjected to a post-deposition annealing treatment, carried out at different Temperature i.e. $500^{\circ} \mathrm{C}, 600^{\circ} \mathrm{C}$ and $700^{\circ} \mathrm{C}$ for 4 hours with heating rate of $5^{\circ} \mathrm{C} / \mathrm{min}$ and one sample subjected at $600^{\circ} \mathrm{C}$ for 4 hours and again at $800^{\circ} \mathrm{C}$ for 1 hours with heating rate of $5^{\circ} \mathrm{C} / \mathrm{min}$. We represent the differently annealed sample with the following symbols:

\begin{tabular}{||cc||}
\hline Sample & Temperature \\
\hline \hline Thin sample annealed at $500^{\circ} \mathrm{C}$ for 4 hours & ANN@500 \\
Thin sample annealed at $600^{\circ} \mathrm{C}$ for 4 hours & ANN@600 \\
Thin sample annealed at $700^{\circ} \mathrm{C}$ for 4 hours & ANN@700 $\mathrm{C}$ \\
Thin sample annealed at $600^{\circ} \mathrm{C}$ and $800^{\circ} \mathrm{C}$ for 4 hours & ANN@600 $\mathrm{C}+800^{\circ} \mathrm{C}$ \\
Thin sample annealed at $500^{\circ} \mathrm{C}$ for 4 hours & ANN@500 $\mathrm{C}$ thick \\
Thin sample annealed at $600^{\circ} \mathrm{C}$ for 4 hours & ANN@600 $\mathrm{C}$ thick \\
Thin sample annealed at $700^{\circ} \mathrm{C}$ for 4 hours & ANN@700 0 thick \\
Thin sample annealed at $600^{\circ} \mathrm{C}$ and $800^{\circ} \mathrm{C}$ for 4 hours & ANN@600 $\mathrm{C}+800^{\circ} \mathrm{C}$ thick \\
\hline
\end{tabular}

The following SEM images show the morphology of the thin films. Samples ANN@500 ${ }^{\circ} \mathrm{C}$ (Figure 1) and ANN@600 $\mathrm{C}$ (Figure 2) show the presence of urchin-like structures, increasing the surface of the catalyst and thus the amount of active sites for the water oxidation.
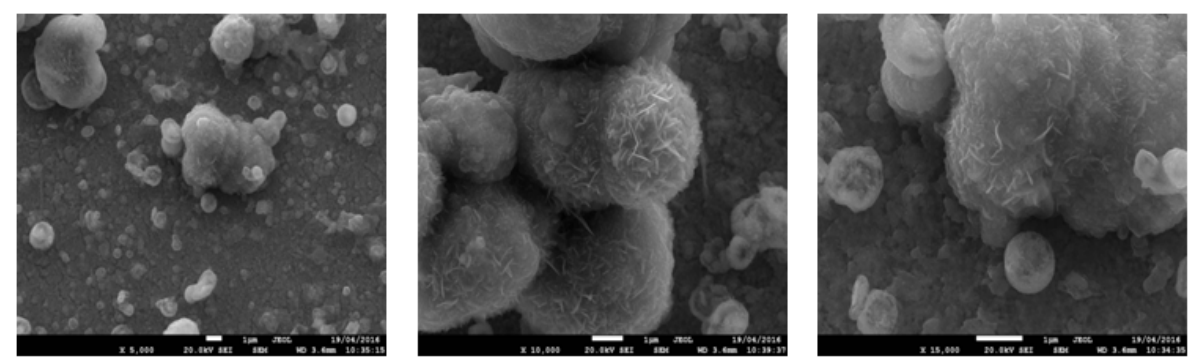

Figure 1. SEM Images Annealing at $500^{\circ} \mathrm{C}$ for 4 hours with heating rate $5^{\circ} \mathrm{C} / \mathrm{min}$

The lengths of needles are not homogeneous, dense and aggregated nanoparticles are found at $600^{\circ} \mathrm{C}$ annealing temperature. Furthermore, SEM images show the nano needle with a non-uniform morphology. Samples show spherical nanoparticles covered with sparse nano flowers. The flower consists of needles petals grown radially from the surface. Probably the roughness present on the core surface is the starting point for the formation of these features. Overall SEM images confirm the urchin like structure on samples ANN@500 ${ }^{\circ} \mathrm{C}$ and ANN@600 ${ }^{\circ} \mathrm{C}$.
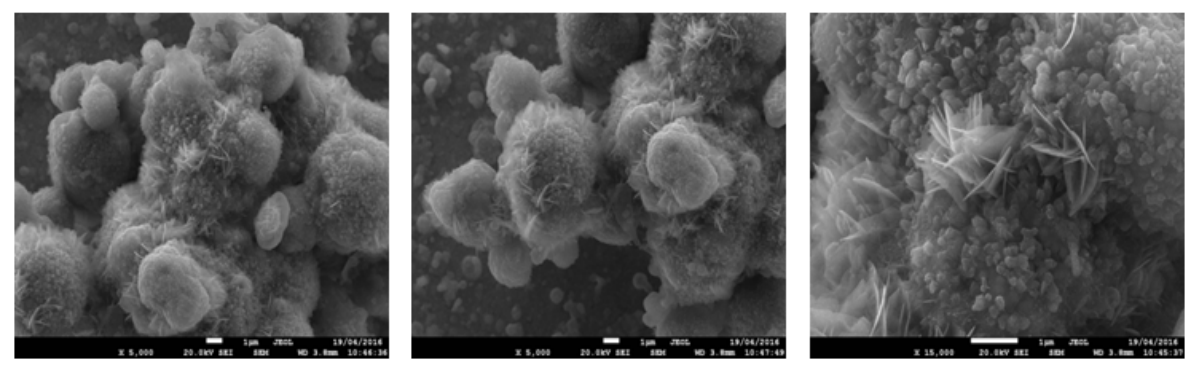

Figure 2. SEM Images Annealing at $600^{\circ} \mathrm{C}$ for 4 hours with heating rate $5^{\circ} \mathrm{C} / \mathrm{min}$ 
Sample ANN@600 $\mathrm{C}+800^{\circ} \mathrm{C}$ (Figure 3) show that there is no developed urchin like structures. At $700^{\circ} \mathrm{C}$ (Figure 4) samples show spherical nanoparticles covered with sparse nano flowers. The flower consists of needles petals grown radially from the surface. Probably the roughness present on the core surface is the starting point for the formation of these features. As will be shown in the following sections, the electrochemical performance of these samples is not good. Here I discuss the thin sample SEM images because these are similar to the thick sample.
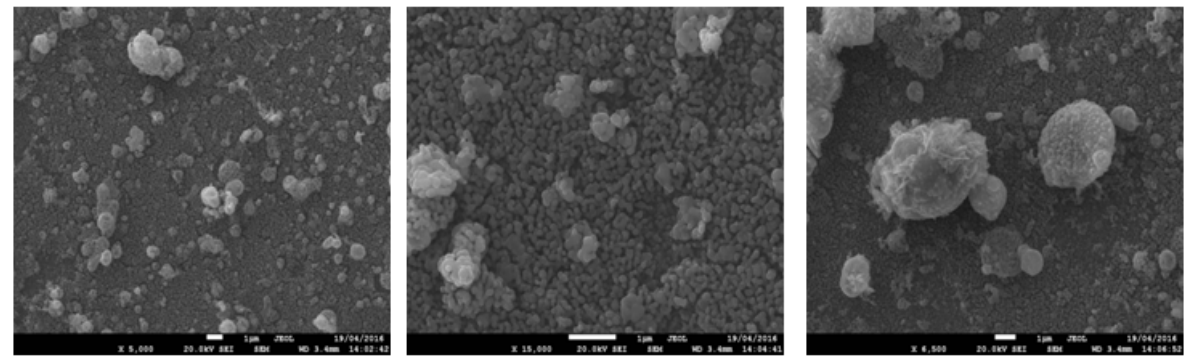

Figure 3. SEM Images Annealing at $600^{\circ} \mathrm{C}$ for 4 hours and at $800^{\circ} \mathrm{C}$ for 1 hour with heating rate $5^{\circ} \mathrm{C} / \mathrm{min}$
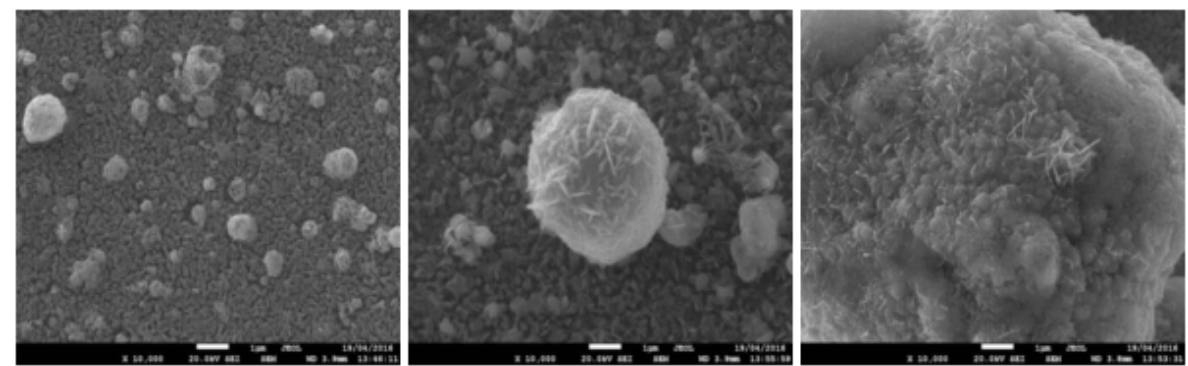

Figure 4. SEM Images Annealing at $700^{\circ} \mathrm{C}$ for 4 hours with heating rate $5^{\circ} \mathrm{C} / \mathrm{min}$

Figure 5 shows the Raman spectra of the $\mathrm{Fe}_{2} \mathrm{O}_{3}$ annealed at different temperature. From the Raman spectra it is confirmed that the hematite modes are present. The peak present at 1070 might be an artifact or an impurity present on the surface of the sample after annealing at $500 \mathrm{C}$ for $4 \mathrm{~h}$. With increasing temperature the peaks became more sharp and visible; clearly indicating the crystallization of the samples.

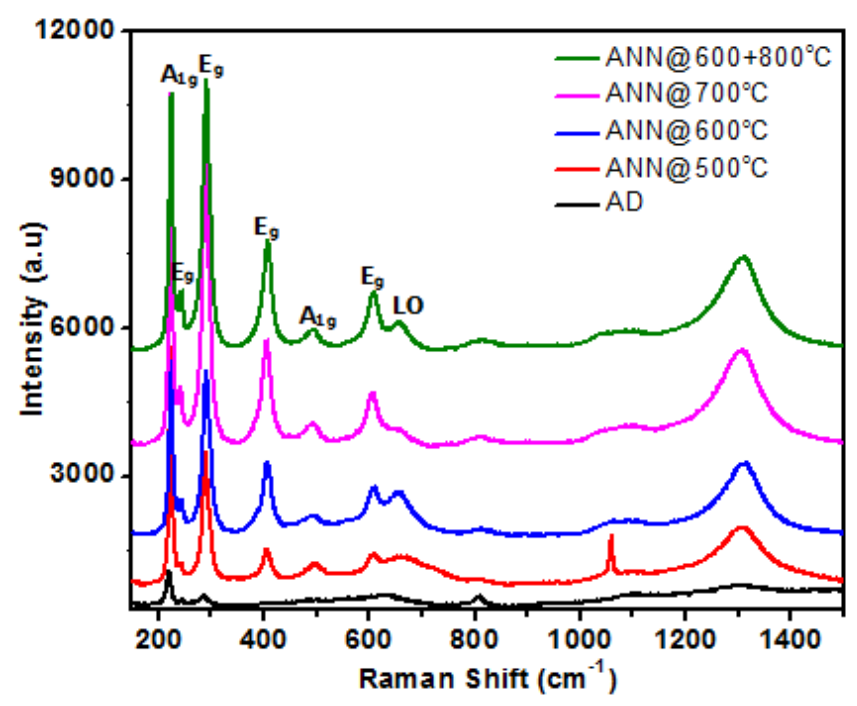

Figure 5. Raman spectra of the sample 


\subsection{Result and Discussion}

Electrochemical water oxidation experiments were performed in a three electrode configuration with a working electrode (Iron oxide thin film on FTO), a platinum mesh as counter electrode and saturated calomel electrode (SCE) as a reference electrode, with Gamry Interface 1000 potentiostate. All the electrodes are immersed in a $\mathrm{KOH}$ electrolyte solution with $\mathrm{pH}=13$. At this $\mathrm{pH}$, oxygen evolution is expected at potential $\mathrm{EO} 2 / \mathrm{H} 2 \mathrm{O}=1.23-(0.059 \mathrm{pH})=0.463 \mathrm{~V}(463 \mathrm{mV})$ versus reversible hydrogen electrode (RHE). The Figure 6 compares the anodic response of various thin electrodes annealed at various temperatures.

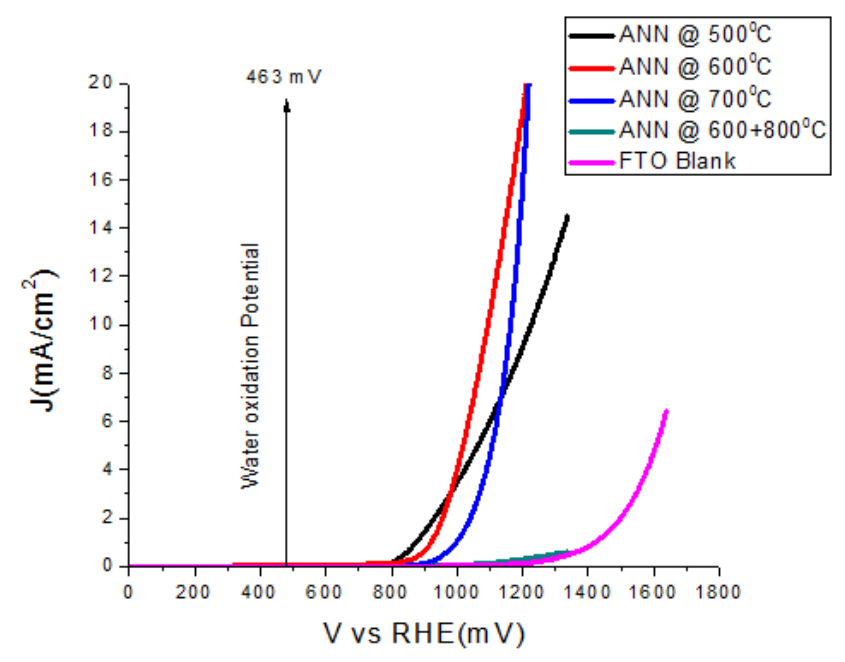

Figure 6. Plots of the current density with respect to the applied potential on the thin electrode.

The oxygen evolution catalysts are required to speed up the reaction rate and reduce the overpotential. Thin Samples ANN@500oC and ANN@600oC shows the response toward the water oxidation at about $0.80 \mathrm{~V}$ vs RHE, with overpotentials of $343.9 \mathrm{mV}$ and $370 \mathrm{mV}$ respectively (taken at $0.2 \mathrm{~mA} / \mathrm{cm} 2$ current density). Moreover, the Tafel slope of the electrode ANN@500 ${ }^{\circ} \mathrm{C}(81.6+0.6 \mathrm{mV} / \mathrm{dec}-1)$ is better than that of the electrode ANN@600 $\mathrm{C}(109.8+0.2 \mathrm{mV} / \mathrm{dec}-1)$, showing good kinetic towards water oxidation. The electrode ANN@700 ${ }^{\circ} \mathrm{C}$ shows the response toward water oxidation at $0.90 \mathrm{~V}$ vs RHE. Moreover, it's provides the $455.6 \mathrm{~V}$ overpotential at $0.2 \mathrm{~mA}$ current density, with Tafel slope $135.8+0.5$. So the efficiency toward the water oxidation is low. Electrode ANN@600 $\mathrm{C}+800^{\circ} \mathrm{C}$ shows the bad catalyst behavior towards the water oxidation (Figure 7).

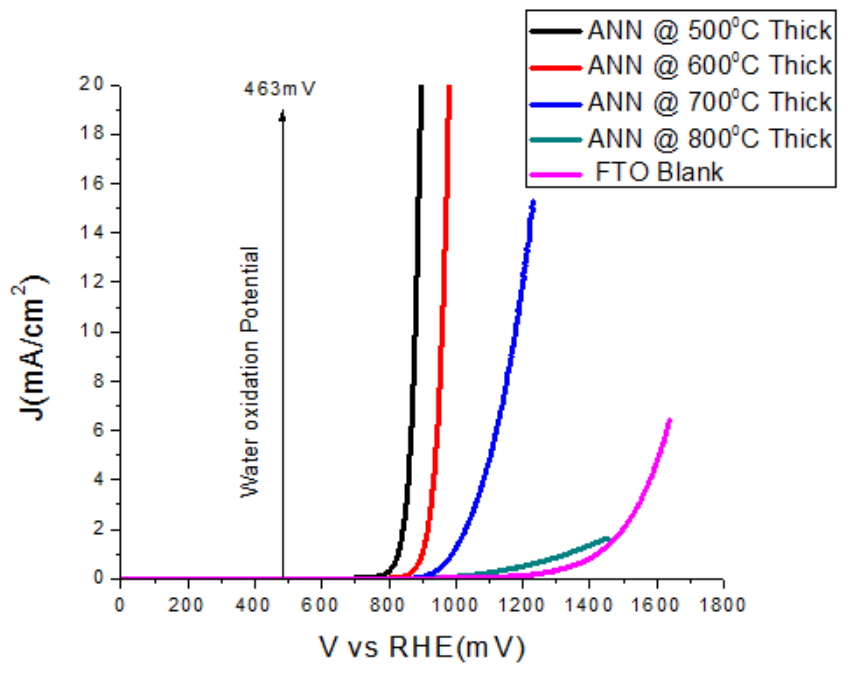

Figure 7. Plots of the current density with respect to the applied potential on the thick electrode

The samples ANN@500 $\mathrm{C}$ and ANN@600 $\mathrm{C}$ show good catalytic performance, in term of overpotential. Large overpotential is associated with slower kinetics for the OER on hematite and with the electronic and 
structural characteristic of the hematite/electrolyte and hematite/substrate interfaces. After increasing the thickness of the film, then again film ANN@500 $\mathrm{C}$ thick and ANN@600 $\mathrm{C}$ thick showed good catalytic performance, both in term of overpotential and tafel slope as compared to the thin films (Table 1). Other samples ANN@700 $\mathrm{C}$ and ANN@600 ${ }^{\circ} \mathrm{C}+800^{\circ} \mathrm{C}$ display the bad catalytic enactment. The detrimental in water oxidation activity for the samples annealed more than $600^{\circ} \mathrm{C}$ could be due to the losing of the conducting properties of FTO. Since, it is clear known that FTO losses its conductivity above $550^{\circ} \mathrm{C}$. Thereby, it is clear that the decreased activity is mainly due to the losing FTO conductivity at high temperature annealing.

The overpotential is calculated as

$$
\text { Overpotential }=V_{\text {Applied }}+0.241-E^{o} \mathrm{O}_{2} / \mathrm{H}_{2} \mathrm{O}
$$

Where $E^{o} \mathrm{O}_{2} / \mathrm{H}_{2} \mathrm{O}=463 \mathrm{mV}$ at $\mathrm{pH}=13$ and the $240 \mathrm{mV}$ term is required to convert the applied potential Vapplied from SCE to RHE (Reversible Hydrogen Electrode). Samples overpotential and Table slopes are shown in Table 1.

Table 1. Overpotentials at various current densities and Table slopes of the thin and thick films annealed at various temperatures.

\begin{tabular}{||ccccc||}
\hline Sample & $\begin{array}{c}\text { Overpotenital } \\
\text { at } 0.2(\mathrm{~mA})\end{array}$ & $\begin{array}{c}\text { Overpotenital } \\
\text { at } 1(\mathrm{~mA})\end{array}$ & $\begin{array}{c}\text { Overpotenital } \\
\text { at } 10(\mathrm{~mA})\end{array}$ & $\begin{array}{c}\text { Tafel slope } \\
\mathrm{mV} / \mathrm{dec}^{-1}\end{array}$ \\
\hline \hline Ann@500 $\mathrm{C}$ thin & 343.9 & 412.4 & 769.8 & $81.6+0.6$ \\
\hline Ann@600 $\mathrm{C}$ thin & 370.0 & 457.0 & 631.1 & $109.8+0.2$ \\
\hline Ann@700 & 455.6 & 534.5 & 699.9 & $135.8+0.5$ \\
\hline Ann@600 $\mathrm{C} \mathrm{C}+800^{\circ} \mathrm{C}$ thin & 708.9 & 103.9 & - & $373.7+2.9$ \\
\hline Ann@500 $\mathrm{C}$ thin & 329.1 & 364.5 & 416.5 & $50.2+0.09$ \\
\hline Ann@600 & 398.8 & 436.6 & 495.6 & $56.0+0.1$ \\
\hline Ann@700 $\mathrm{C}$ thin & 363.5 & 526.4 & 414.4 & $83.2+0.7$ \\
\hline Ann@6600 $\mathrm{C}+800^{\circ} \mathrm{C}$ thin & 615.2 & 865.0 & - & $258.8+2.8$ \\
\hline
\end{tabular}

The significant difference in table slopes between thin and thick samples ANN@5000C and ANN@600oC could either depend on a different composition of the material (e.g. quantity of magnetite present) or simply be an effect of the different morphology, more porous in the case of thick samples.

\section{Tafel analysis}

The Tafel slope is also an important measure of electrode performance, because it accounts for changes in mechanism at different overpotential.

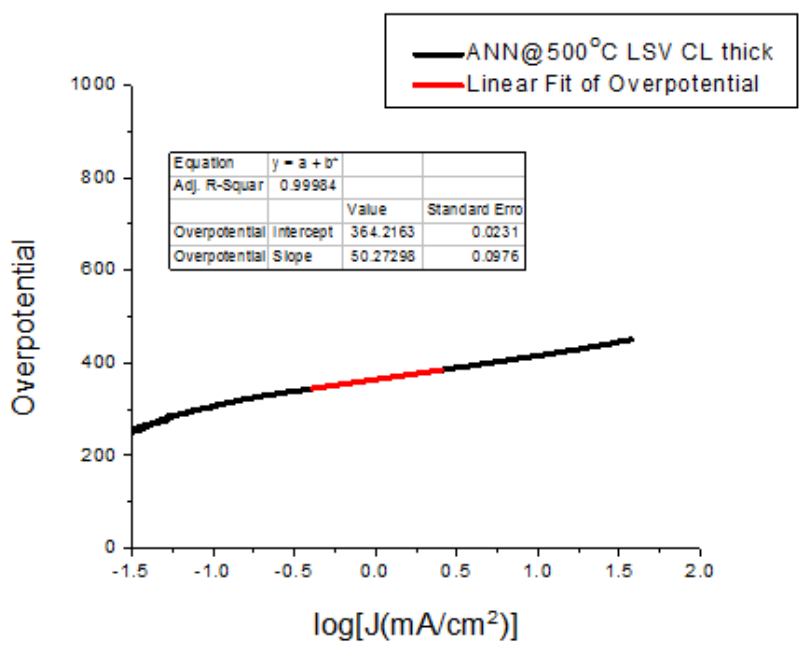

Figure 8. Tafel slope of sample ANN@500 C thick 
We calculate Tafel slope according to the Tafel equation (Figure 8), which applies in the voltage region where the forward reaction (OER) is predominant compared to the backward reaction (HER). Figure 8 show the Tafel slope of best performing ANN@500 $\mathrm{C}$ thick electrode.

\section{Chronoamperometries}

A good OER catalyst that use in the water splitting device must satisfy the two basic requirement. First it must be highly active towards its respective reaction. Secondly it must be stable in the oxidation condition and maintain the efficiency over the time scale for commercial use.

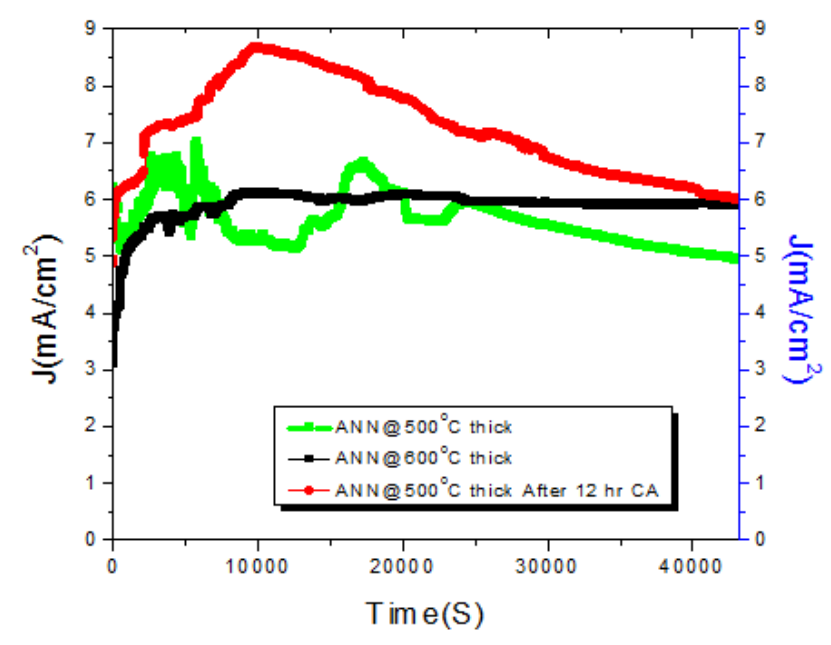

Figure 9. $12 \mathrm{~h}$ Chronoamperometries of thick sample ANN@500 $\mathrm{C}, \mathrm{ANN} @ 600^{\circ} \mathrm{C}$ and again $12 \mathrm{~h}$ ANN@500 $\mathrm{C}$

The 12 hours chronoamperometries were performed for checking the long term stability of the best performing samples: ANN@500oC thick and ANN@600 $\mathrm{C}$ thick (Figure 9). In the first 2.8 hours the current density of the ANN@600oC thick electrode is increased, then it remains stable at $6 \mathrm{~mA} / \mathrm{cm} 2$ for next 9.2 hours. In the case of the ANN@500 $\mathrm{C}$ thick electrode, in the first 6 hours the current density fluctuates between7 $\mathrm{mA} / \mathrm{cm} 2$ and $5 \mathrm{~mA} / \mathrm{cm} 2$ and then gradually decreases from $5.5 \mathrm{~mA} / \mathrm{cm} 2$ to $5 \mathrm{~mA} / \mathrm{cm} 2$. It could be due to the bubbles formation on the surface of the electrode.The same pattern is detected when repeating the experiment a second time on the same electrode.

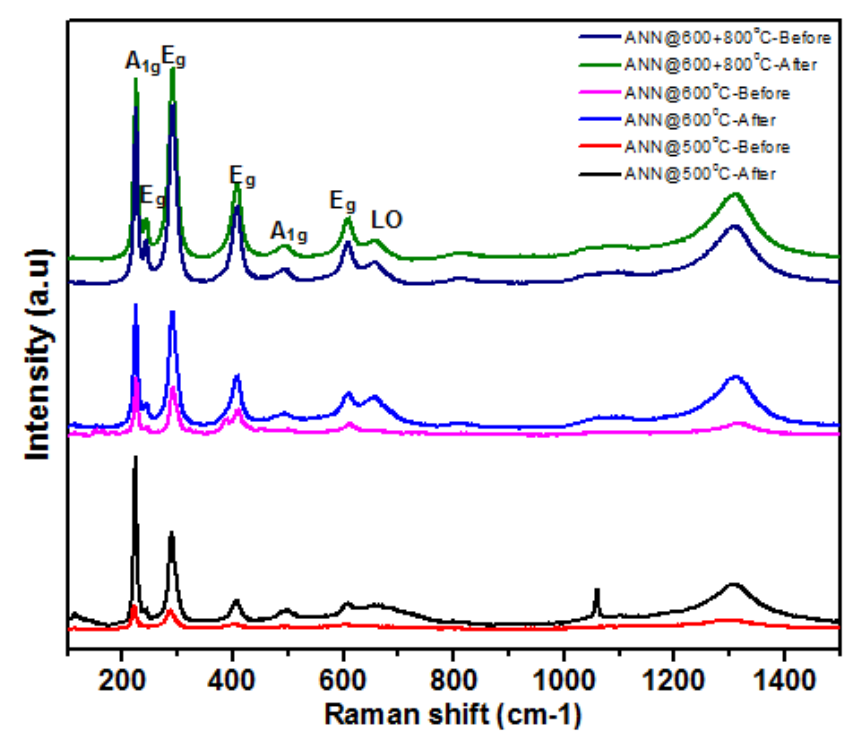

Figure 10. Raman spectra of the sample before and after water oxidation. 
Before and after water oxidation the miro-Raman spectra for all the samples are represented in the Figure 10. It is indicating that after water oxidation the peak intensities were reduced, the probable reason could be due to the surface coverge of the electrolyte. However, the phase and crystallinity of the all the samples were well preserved ever after water oxidation, showing that the prepared thin film samples are highly stable to the water oxidation experiments.

\section{Conclusion}

We investigated that the Iron oxide ( $\alpha$-hematite) was showing promising catalytic activity towards the oxygen evolution reaction and can be employed as anode in electrocatalytic water splitting techniques for hydrogen production. The best performing electrodes showed an overpotential@0.2 mA/cm2 of about 330 $\mathrm{mV}$ and a Tafel slope of $50 \mathrm{mV} / \mathrm{dec}$. These electrode metrics are in line with those of current state-of-the-art materials like $\mathrm{IrO}_{2}$ or CoPi. We observe that the deposition of more material, e.g 10000 instead of 5000 pulses, leads to better overpotentials and Tafel slopes, indicating that the performance can be enhanced simply by increasing the catalyst loading. That is normally not possible for bulk-like thick films or even thin-films where the surface coverage is already complete and in the present case it is likely resulting from the hierarchical 3D structure.

Author Contributions: All authors contributed equally to the writing of this paper. All authors read and approved the final manuscript.

Conflicts of Interest: "The authors declare no conflict of interest."

\section{References}

[1] Allison, I., Bindoff, N. L., Bindschadler, R. A., Cox, P. M., de Noblet, N., England, M. H., \& Kaser, G. (2011). The Copenhagen Diagnosis: Updating the world on the latest climate science. Elsevier.

[2] Stoll, T., Zafeiropoulos, G., \& Tsampas, M. N. (2016). Solar fuel production in a novel polymeric electrolyte membrane photoelectrochemical (PEM-PEC) cell with a web of titania nanotube arrays as photoanode and gaseous reactants. International Journal of Hydrogen Energy, 41(40), 17807-17817.

[3] Oppenheim, J., \& Beinhocker, E. D. (2009). Climate change and the economy: myths versus realities. McKinsey \& Company, available at http://www. euractiv. com/25/images/Climate change myths. pdf (accessed on 15 July 2009).

[4] Lewis, N. S., \& Nocera, D. G. (2006). Powering the planet: Chemical challenges in solar energy utilization. Proceedings of the National Academy of Sciences, 103(43), 15729-15735.

[5] Gondal, M. A., Hameed, A., Yamani, Z. H., \& Suwaiyan, A. (2004). Production of hydrogen and oxygen by water splitting using laser induced photo-catalysis over Fe2O3. Applied Catalysis A: General, 268(1-2), 159-167.

[6] Balu, A. M., Pineda, A., Yoshida, K., Campelo, J. M., Gai, P. L., Luque, R., \& Romero, A. A. (2010). Fe/Al synergy in Fe 2 O 3 nanoparticles supported on porous aluminosilicate materials: excelling activities in oxidation reactions. Chemical Communications, 46(41), 7825-7827.

[7] Warang, T., Patel, N., Santini, A., Bazzanella, N., Kale, A., \& Miotello, A. (2012). Pulsed laser deposition of Co3O4 nanoparticles assembled coating: Role of substrate temperature to tailor disordered to crystalline phase and related photocatalytic activity in degradation of methylene blue. Applied Catalysis A: General, 423, 21-27.

[8] Guo, Q., Shi, W., Liu, F., Arita, M., Ikoma, Y., Saito, K., \& Nishio, M. (2013). Effects of oxygen gas pressure on properties of iron oxide films grown by pulsed laser deposition. Journal of Alloys and Compounds, 552, 1-5.

[9] Gower, M. C. (2000). Industrial applications of laser micromachining. Optics Express, 7(2), 56-67.

[10] Cristino, V., Berardi, S., Caramori, S., Argazzi, R., Carli, S., Meda, L., \& Bignozzi, C. A. (2013). Efficient solar water oxidation using photovoltaic devices functionalized with earth-abundant oxygen evolving catalysts. Physical Chemistry Chemical Physics, 15(31), 13083-13092.

[11] Van de Krol, R., \& Grtzel, M. (2012). Photoelectrochemical hydrogen production (Vol. 90). New York: Springer.

[12] Horowitz, G. (1983). Capacitance-voltage measurements and flat-band potential determination on Zr-doped a-Fe2O3 single-crystal electrodes. Journal of electroanalytical chemistry and interfacial electrochemistry, 159(2), 421-436.

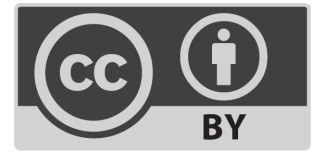

(C) 2019 by the authors; licensee PSRP, Lahore, Pakistan. This article is an open access article distributed under the terms and conditions of the Creative Commons Attribution (CC-BY) license (http://creativecommons.org/licenses/by/4.0/). 